\title{
Application of Fuzzy Decision-Making Methods in the NBA Team Ranking
}

\author{
Yuanyuan Dong ${ }^{\mathrm{a}}$, Chengrong $\mathrm{Xie}^{\mathrm{a}}$, Cheng Wang ${ }^{\mathrm{b}}$ \\ a Department of Maths and Finance, Yunyang Teachers' College, \\ Shiyan 442000, Hubei, China; \\ ${ }^{b}$ College of Mathematics and Computer Science, Huanggang Normal University, \\ Huanggang 438000, China \\ xyliaohg@foxmail.com
}

\section{Keywords: Fuzzy decision-making; Team Ranking; Borda Number}

Abstract. In this paper, a simple decision-making model has been established based on the method of fuzzy opinion centralized decision, and the date about the NBA teams of Weston part has been analyzed. In this model, the Borda number method and weighted Borda number method are presented to rank the capability of NBA teams of Weston part, and a satisfactory ranking result is obtained.

\section{Introduction}

Fuzzy decision- making is decision process of choosing a satisfactory one from many research objects, or a ranking process for many research objects according to some given rules. The fuzzy ranking of team's capability, is not identical for different fans, but in some certain conditions we need scientific analysis and evaluation for the team's capability, such as the team's technical statistics data (Score, Rebound, Offensive and Defensive Deficit, Assist, Steals, Block Shot, Turnover, etc.). To rank the team's overall capability, the traditional methed is to simply sum the technical statistics for the technical achievement, and then determine the team with the highest score as the best team. By using the same method, we can get all ranking results fo all team. This method is easy to operate, and have a strong intuitive, but it can cause a lot of useful and scientific information losing [1]. In order to overcome this defect, in this paper, the scientific method has been used for sorting, analyzing and mining the team's technical statistical data of western part, and the overall capability of NBA teams of western part has been analyzed finally by using the method of fuzzy opinion centralized decision, and then the ranking results of team's overall capability is obtained. The results showed that the ranking order is reasonable.

\section{Method of Fuzzy Opinion Centralized Decision}

In this paper, we used seven technical indexes referred in the introduction, and supposed that the capability of some western teams belongs to the above index system. We will take the elements of some western teams in order, and choose $m$ specialists to form an expert group. Each specialist in the expert group gives an order according to the elements in the set $U$, and we can get the $m$ orders of fuzzy suggestions and regard it as a set $V=\left(v_{1}, v_{2}, \ldots, v_{m}\right),\left(v_{i}\right.$ means that the order of fuzzy suggestions given by the $i$ th specialist). How to transform the fuzzy opinion sequences into a reasonable opinion called " method of fuzzy opinion centralized decision " as follows.

Supposed that $u \in U, B_{i}(u)$ means that the numbers of elements which is after $u$ in the $i$ th fuzzy opinion sequence $v_{i}$, for example, if $u$ is in the first place in the ith fuzzy opinion sequence $v_{i}$, $B_{i}(u)=n-1$. If $u$ is in the second place in the $i$ th fuzzy opinion sequence $v_{i}, B_{i}(u)=n-2$, and so on. If $u$ is in the $k$ th place in the ith fuzzy opinion sequence $v_{i}, B_{i}(u)=n-k$. We consider $B(u)=\sum_{i=1}^{m} B_{i}(u)$ as Borda number [2]. It is obvious to understand that $B(u)$ denotes the team $U$ 's 
overall score in each order $v_{1}, v_{1}, \ldots, v_{m}$. As a result, we take the elements which stand for all different teams in the domain in order according to the size of Borda number, and this order use s a relatively reasonable opinion after Method of Fuzzy Opinion Centralized Decision. It is easy to operate in practice and make comprehensive evaluation of fuzzy decision quickly, [3-4] and it also has some disadvantages. For example, when its outcomes derived from this method don't conform to the actual value, and it may be caused by the different effects of the elements in the domain on the evaluation targets. In order to avoid this disadvantage, we introduced weighted Borda number:

$$
B(u)=\sum_{i=1}^{m} \alpha_{i} B_{i}(u), \text { and } \sum_{i=1}^{m} \alpha_{i}=1 \text {. }
$$

\section{Example Analysis}

Data from the technical statistics of the western part of the 07/08 NBA season has been used, Fuzzy opinion of centralized decision method has been used to rank each team's technical statistics, as Table 1. In Table $1, u_{i}$ stands for the total score ranking $(i=1,2, \ldots, 10)$.

The process is as follows:

(1) The set of 10 teams structural scheme is denoted as $U=\left(u_{1}, u_{2}, \ldots, u_{10}\right)$.

(2) 7 technical statistics has been ranked with values, and experts fuzzy opinion set has been denoted as $V=\left(v_{1}, v_{2}, \ldots, v_{7}\right)$.

(3) Calculate each team's Borda number.

(4) Rank the capability of teams of western part according to the values of Borda number.

According to Table 2, take $u_{1}$ for example: the score of $u_{1}$ ranking the third, so $u_{1}$ is ranking the third one as the first way, and $B_{1}\left(u_{1}\right)=10-3=7$. But $u_{1}$ is ranking the fourth one as the second way.

$B_{2}\left(u_{1}\right)=10-4=6$ likely, put the data for the expert opinion matrix's first column.

The $B_{7 \times 10}$ expert opinion matrix is given as follows.

$\left(\begin{array}{llllllllll}7 & 6 & 4 & 8 & 9 & 1 & 5 & 0 & 2 & 3 \\ 6 & 9 & 1 & 7 & 3 & 5 & 0 & 8 & 2 & 4 \\ 9 & 2 & 7 & 1 & 0 & 8 & 3 & 6 & 5 & 4 \\ 9 & 4 & 7 & 6 & 8 & 2 & 3 & 1 & 5 & 0 \\ 8 & 3 & 7 & 9 & 1 & 4 & 5 & 2 & 0 & 6 \\ 3 & 8 & 2 & 9 & 5 & 1 & 4 & 7 & 0 & 6 \\ 3 & 5 & 4 & 0 & 7 & 6 & 9 & 2 & 8 & 1\end{array}\right)$.

Sum up each element of this matrix's column, we can get $u_{i}$ 's Borda number. To calculate simply, we use $C++$ program and then we get $B_{u_{1}}=45, B_{u_{2}}=37, B_{u_{3}}=32, B_{u_{4}}=40, B_{u_{5}}=33, B_{u_{6}}=27$, $B_{u_{7}}=29, B_{u_{8}}=26, B_{u_{9}}=22, B_{u_{10}}=24$. So the new order is $u_{1}, u_{4}, u_{2}, u_{5}, u_{3}, u_{7}, u_{6}, u_{8}, u_{10}, u_{9}$. Obviously, a part of the team's rank has changed, such as $u_{2}$ and $u_{4}$. Furthermore, each factor of $u_{2}$ 's ranking: 4, 1, 8, 6, 7, 2, 5. Among them, rebound, block shot rank ahead $(1,2)$, but it's score, steals $(4$, 7) lower than $u_{4}$. The rank of $u_{4}$ 's each statistic capability is: $2,3,8,4,1,1,10$, and relatively stable. So this rank that contain each statistic capability is reasonable. In addition, we can see $u_{1}, u_{3}, u_{5}, u_{6}$ can enter the playoffs.

It easy to explain why $u_{1}, u_{3}$ could enter the playoffs, but it cannot explain why $u_{5}, u_{6}$ could enter the playoffs. For further analysis it can be find, the offensive and defensive deficit and turnover of $u_{6}$ rank ahead, if the team want enter the playoffs, the first thing is to have good defensive. In other words, turnover and defensive are very important. Also, we consider the weighted Borda number, score, rebound, Offensive and Defensive Deficit, Assist, Steals, Block Shot, Turnover, the 
corresponding weights are $2,1,5,2,1,1,5$, and the fuzzy vector is $W=\left(\frac{2}{17}, \frac{1}{17}, \frac{5}{17}, \frac{2}{17}, \frac{1}{17}, \frac{1}{17}, \frac{5}{17}\right)$. From $B(u)=\sum_{i=1}^{m} \alpha_{i} B_{i}(u)$, each team's Weighted Borda number can be calculated. Then rank with Weighted Borda number is $u_{1}, u_{5}, u_{3}, u_{6}, u_{7}, u_{9}, u_{2}, u_{8}, u_{4}, u_{10}$. Clearly, a part of team's ranking has changed, and it can explain why $u_{6}$ can enter the playoffs, $u_{2}$ and $u_{4}$ stop and have no chance for the finals can be explained as well.

Table 1. The technical statistics of the western part of the $07 / 08$ NBA season

\begin{tabular}{|c|c|c|c|c|c|c|c|c|}
\hline Team & $\begin{array}{c}\text { Score } \\
v_{1}\end{array}$ & $\begin{array}{c}\text { Rebound } \\
v_{2}\end{array}$ & $\begin{array}{c}\text { Offensive } \\
\text { and } \\
\text { Defensive } \\
\text { Deficit } \\
v_{3}\end{array}$ & $\begin{array}{c}\text { Assist } \\
v_{4}\end{array}$ & $\begin{array}{c}\text { Steals } \\
v_{5}\end{array}$ & $\begin{array}{c}\text { Block } \\
\text { Shot } \\
v_{6}\end{array}$ & $\begin{array}{c}\text { Turnove } \\
v_{7}\end{array}$ & $\begin{array}{l}\text { Total } \\
\text { Score }\end{array}$ \\
\hline Utah Jazz $u_{1}$ & 96.7 & 42.6 & -90.1 & 25.5 & 8.6 & 4 & -15.4 & 71.900 \\
\hline $\begin{array}{c}\text { Dallas } \\
\text { Mavericks } u_{2}\end{array}$ & 95.5 & 46 & -99.1 & 19.9 & 7 & 4.9 & -13.5 & 60.700 \\
\hline $\begin{array}{c}\text { Charlotte } \\
\text { Hornets } \\
u_{3}\end{array}$ & 95.1 & 38.9 & -93 & 21.1 & 8.3 & 4 & -14.3 & 60.100 \\
\hline $\begin{array}{c}\text { Denver Nuggets } \\
u_{4}\end{array}$ & 99.3 & 43.1 & -101.6 & 21 & 9.1 & 5.3 & -16.6 & 59.600 \\
\hline $\begin{array}{c}\text { Minnesota } \\
\text { Timberwolves } \\
u_{5}\end{array}$ & 100.7 & 41.3 & -105.6 & 24.4 & 6 & 4.7 & -11.9 & 59.600 \\
\hline $\begin{array}{c}\text { Houston } \\
\text { Rockets } \\
u_{6}\end{array}$ & 91.6 & 42.3 & -91.3 & 17.4 & 7.3 & 3.1 & -12.9 & 57.500 \\
\hline $\begin{array}{c}\text { Portland Trail } \\
\text { Blazers } \\
u_{7}\end{array}$ & 95.3 & 38.8 & -99 & 19.4 & 7.3 & 4.6 & -11 & 55.400 \\
\hline $\begin{array}{c}\text { Seattle } \\
\text { Supersonics } \\
u_{8}\end{array}$ & 90.4 & 45.2 & -97.1 & 16 & 6.8 & 4.9 & -15.8 & 50.400 \\
\hline $\begin{array}{c}\text { San Antonio } \\
\text { Spurs } \\
u_{9}\end{array}$ & 92.1 & 39.9 & -98.1 & 20.4 & 3.7 & 2.7 & -11.3 & 49.400 \\
\hline $\begin{array}{c}\text { Ancouver } \\
\text { Grizzlies } \\
u_{10}\end{array}$ & 92.8 & 42.2 & -98.2 & 15.8 & 7.9 & 4.8 & -16.6 & 48.700 \\
\hline
\end{tabular}


Table 2. The technical ranking of the westem part of the 07/08 NBA season

\begin{tabular}{ccccccccccc}
\hline & One & Two & Three & Four & Five & Six & Seven & Eight & Nine & Ten \\
\hline$v_{1}$ & $u_{5}$ & $u_{4}$ & $u_{1}$ & $u_{2}$ & $u_{7}$ & $u_{3}$ & $u_{10}$ & $u_{9}$ & $u_{6}$ & $u_{8}$ \\
$v_{2}$ & $u_{2}$ & $u_{8}$ & $u_{4}$ & $u_{1}$ & $u_{6}$ & $u_{10}$ & $u_{5}$ & $u_{9}$ & $u_{3}$ & $u_{7}$ \\
$v_{3}$ & $u_{1}$ & $u_{6}$ & $u_{3}$ & $u_{8}$ & $u_{9}$ & $u_{10}$ & $u_{7}$ & $u_{2}$ & $u_{4}$ & $u_{5}$ \\
$v_{4}$ & $u_{1}$ & $u_{5}$ & $u_{3}$ & $u_{4}$ & $u_{9}$ & $u_{2}$ & $u_{7}$ & $u_{6}$ & $u_{8}$ & $u_{10}$ \\
$v_{5}$ & $u_{4}$ & $u_{1}$ & $u_{3}$ & $u_{10}$ & $u_{7}$ & $u_{6}$ & $u_{2}$ & $u_{8}$ & $u_{5}$ & $u_{9}$ \\
$v_{6}$ & $u_{4}$ & $u_{2}$ & $u_{8}$ & $u_{10}$ & $u_{5}$ & $u_{7}$ & $u_{1}$ & $u_{3}$ & $u_{6}$ & $u_{9}$ \\
$v_{7}$ & $u_{7}$ & $u_{9}$ & $u_{5}$ & $u_{6}$ & $u_{2}$ & $u_{3}$ & $u_{1}$ & $u_{8}$ & $u_{10}$ & $u_{4}$ \\
\hline
\end{tabular}

\section{Conclusions}

In this paper, the Borda number and Weighted Borda number have been used to rank the overall capability of NBA teams of western part twice. The ranking results can be a good real to reflect the team's overall capability. The presented method is simple and effective, and has very strong maneuverability. If we want to analyze the overall capabilities of more NBA teams, we can use the computer to do this calculating work.

\section{Acknowledgments}

This work is supported by the Natural Science Foundation of Hubei Province (No.2014CFC1096), and the 2014 Key Project of Hubei Provincial Department of Education (No.D20142903).

\section{References}

[1] D. Y. Cai, Some comments about team ranking problem, Mathematics in Practice and Theory 2 (1994) 95-96.

[2] J.J. Xie, C.P. Liu, Fuzzy mathematics method and its application, Press of Huazhong University of Science and Technology, WuHan, 2006.

[3] X.Y. Ma, Fuzzy comprehensive evaluation in the students' quality cultivation of the application system, College Mathematics 19 (2003) 42-43.

[4] J.B. Ye, The fuzzy comprehensive evaluation of students' comprehensive quality, Systems Engineering Theory and Practice 9 (2000) 91-98.

[5] Y. Chen, W.P. Ding, The fuzzy decision-making method of college students' mathematicalquality, Journal of Hunan Institute of Technology 21 (2008) 14-16.

[6] J.J. Li, G.Q. Chen, The fuzzy opinion centralized decision method and its application research, Journal of Shangqiu Normal College 21 (2005) 76-77. 